\title{
Methotrexate Based Regimen versus Post-Transplant Cyclophosphamide in Allogeneic Hematopoietic Stem Cell Transplantation (Clinical Outcome), Egyptian Experience Rasha I. Ibrahim ${ }^{1}$, George B. Soryal ${ }^{2}$, Haydi S. Mohamed ${ }^{1}$ \\ ${ }^{1}$ Department of Internal Medicine and Clinical Hematology, Ain Shams University, Cairo, Egypt \\ ${ }^{2}$ Department of Clinical Hematology, El Maadi Medical Compound, Cairo, Egypt. \\ *Corresponding author: Haydi Sayed Mohamed, Mobile: (+20)01001357036, Email: haydisayed@ hotmail.com
}

\begin{abstract}
Background: Graft-versus-host disease (GVHD) is the major complication after allogeneic hematopoietic stem cell (HSCT) transplantation. GVHD prophylaxis is based on the use of calcineurin inhibitors. With the use of haploidentical HSCT, the use of cyclophosphamide increased after implantation (PT-Cy).

Objectives: Compare the clinical outcome of allogeneic HSCT after PT-Cy versus methotrexate (MTX) based regimens

Patients and methods: we included 137 patients from Bone Marrow Transplantation Units who received allogeneic HSCT. They were divided into 2 groups according to GVHD prophylaxis protocol: (group 1) included 102 patients received (MTX) and cyclosporine (CSA) and (group 2) included 35 patients who received PT-Cy in combination with (CSA) and mycophenolate-mofetil (MMF).

Results: Neutrophil engraftment in group 1 at day $12.91 \pm 5.67$ vs at day14.69 \pm 2.57 in group 2 . The mean day of platelet recovery was $14.67 \pm 1.89$ and $14.69 \pm 5.48$ in group 1 and 2 respectively. Incidence of acute (a) GVHD at day 100 was $31.4 \%$ in group 1 vs $28.6 \%$ in group 2 . The use of PT-CY reduced the risk of extensive chronic (c) GVHD to $17.1 \%$ (group 2) with high statistical significance ( $\mathrm{p}$ Value $<0.001$ ). Overall survival (OS) at 5 years was $40.2 \%, 53.6 \%$ in group 1 and 2 respectively $(\mathrm{p}$ value $=0.76$ ), while disease free survival $(\mathrm{DFS})$ was $(81.3 \%$ vs $71.2 \%$, p value 0.32 ).
\end{abstract}

Conclusion: The use of PT-Cy reduces the risk of extensive cGVHD.

Keywords: GVHD, HSCT, PT-CY.

\section{INTRODUCTION}

Allogeneic HSCT is considered the main curative process for hematologic malignancy ${ }^{(\mathbf{1})}$. GVHD is the leading cause of morbidity and mortality. Acute GVHD occurs in $40 \%$ of transplants while chronic GVHD occurs in $10 \%$ up to $80 \%$ of cases. The current preventive systems are striking for developing alternative regimes ${ }^{(2)}$.

The use of calcineurin inhibitors in combination with other immunosuppressive (IS) drugs is the standard preventative regimen for GVHD. With increasing use of matched donor in HSCT, high-dose cyclophosphamide post-transplantation (PT-Cy) has been used in conjunction with other IS drugs such as prevention of GVHD and reporting a low incidence of acute (a) and chronic (c) GVHD and reduced transplant-related mortality ${ }^{(2)}$.

The main impact of cyclophosphamide on T cells unlike other immunosuppressive agents is its ability to induce apoptosis and increase the regulation of Fas (CD95) expression, resulting in activation-induced cell death within 6 days of activation ${ }^{(3,4)}$.

The aim of this study was to compare the clinical outcome of allogeneic HSCT after PT-Cy versus methotrexate based regimens.

\section{PATIENTS AND METHODS}

The study was conducted on 137 patients aged from 16-65 years old with benign and malignant hematological diseases from Bone Marrow
Transplantation Unit who were subjected to allogeneic HSCT from matched related and haploidentical donor in first or second complete remission (CR) according to disease state and risk stratification. Transplant was held between 2014-2019 with median follow up 60 months.

\section{Ethical approval:}

A written informed consent was obtained from all the study participants along with the approval of the study by the Ethics Committee Board, Faculty of medicine, Ain Shams University. The study conformed to the stipulations of Declaration of Helsinki 1964.

The patients were divided into 2 groups according to GVHD prophylaxis that they had been received: Group $1(n=102)$ received MTX and CSA and Group $2(\mathrm{n}=35)$ received PT-Cy, MMF and CSA.

All patients received allogeneic transplant were subjected to the following pre transplant work up, which included CBC, ABO Blood Group test, Kidney function tests, Liver function and prothrombin activity, HBV DNA by PCR, HCV RNA by PCR, CMV Antibodies (IgM and $\operatorname{IgG}$ ), Bone marrow aspiration and radiological investigations in form of chest $\mathrm{X}$ ray, pulmonary function tests, abdominal ultrasonography and Echocardiography.

Patients were isolated in HEPA filter cube and received conditioning regimens in form of fludarabine 
$30 \mathrm{mg} / \mathrm{m}^{2} /$ day from day -6 to day -2 from stem cell infusion (day zero) and busulfan $4 \mathrm{mg} / \mathrm{kg} /$ day from day -4 to day -2 , etoposide $15 \mathrm{mg} / \mathrm{kg} /$ day from day -6 to day-2 and aplastic anemia patients received fludarabine $30 \mathrm{mg} / \mathrm{m}^{2} /$ day from day -6 to day -2 and cyclophosphamide $140 \mathrm{mg} / \mathrm{kg}$ divided at days $-6,-4,-2$ and anti thymocyte globulin (ATG) $2.5 \mathrm{mg} / \mathrm{Kg}$ at days $-5,-3,-1$.

Group 1 received CNI from day -1 to day +120 at least, MTX $10 \mathrm{mg} / \mathrm{m}^{2}$ on days $+2,+4,+6$, while Group 2 received PT-Cy $50 \mathrm{mg} / \mathrm{kg}$ at day +3 and day +4 , CNI from day +5 today +60 , MMF from day +5 to day +35 as GVHD prophylaxis post-transplant.

Patients were followed up for 60 months and comparative study was held between both groups as regard engraftment, GVHD, CMV reactivation, relapse, overall survival, disease free survival, nonrelapse mortality and complications related to organs damage.

Neutrophil recovery was defined as the first of 3 consecutive days with an absolute neutrophil count (ANC) greater than $0.5 \times 10^{9} / \mathrm{L}$. Platelet recovery was defined as a platelet count greater than $20 \times 10^{9} / \mathrm{L}$ without platelet transfusion in the preceding 7 days.
Donor chimerism was assessed using a polymerase chain reaction, on days $30,60,180$, and 360 after transplantation, and then on a yearly basis.

Diagnosis and grading of acute and chronic GVHD was defined based on standard criteria ${ }^{(5,6,7)}$.

\section{Statistical analysis}

Data were collected, revised, coded and entered to the Statistical Package for the Social Sciences (IBM SPSS) version 20. The quantitative data were presented as mean, standard deviations and ranges and compared by independent t-test. Qualitative variables were presented as number and percentages and compared by Chi-square test. Kaplan-Mayer analysis was used to assess the relation with overall survival by using Log-Rank test. The confidence interval was set to $95 \%$, the p-value was considered significant as follows: $\mathrm{P}>0.05$ : Non significant $(\mathrm{NS}), \mathrm{P} \leq 0.05$ : Significant (S), $\mathrm{P} \leq 0.01$ : Highly significant (HS).

\section{RESULTS}

Table 1 summarizes the characteristics of the patients included in the study who were divided into 2 groups.

Table (1): Demographic data of studied groups

\begin{tabular}{|l|c|c|c|c|}
\hline & \multicolumn{2}{|c|}{ Group I, No. = 102 } & \multicolumn{2}{c|}{ Group II, No. = 35 } \\
\cline { 2 - 5 } & No. & \% & No. & \% \\
\hline Age: & & & & \\
$16-25$ y & 41 & $40.2 \%$ & 17 & $48.6 \%$ \\
$25-35$ y & 38 & $37.3 \%$ & 7 & $20.0 \%$ \\
$35-45$ y & 18 & $17.6 \%$ & 8 & $22.9 \%$ \\
$45-55$ y & 4 & $3.9 \%$ & 3 & $8.6 \%$ \\
$55-65$ y & 1 & $1.0 \%$ & 0 & $0.0 \%$ \\
\hline Sex: & 42 & $41.2 \%$ & 8 & $22.9 \%$ \\
Females & 60 & $58.8 \%$ & 27 & $77.1 \%$ \\
Males & & & & \\
\hline Diagnosis: & 42 & $41.2 \%$ & 26 & $74.3 \%$ \\
AML & 27 & $26.5 \%$ & 1 & $2.9 \%$ \\
ALL & 16 & $15.7 \%$ & 2 & $5.7 \%$ \\
Aplastic anemia & 7 & $6.9 \%$ & 3 & $8.6 \%$ \\
CML & 5 & $4.9 \%$ & 1 & $2.9 \%$ \\
MDS & 3 & $2.9 \%$ & 0 & $0.0 \%$ \\
Biphenotypic acute leukemia & 2 & $2.0 \%$ & 1 & $2.9 \%$ \\
NHL & 0 & $0.0 \%$ & 1 & $2.9 \%$ \\
MM & & & & \\
\hline Donor type: & & $100.0 \%$ & 21 & $60 \%$ \\
Allo fully matched & 0 & $0.0 \%$ & 14 & $40.0 \%$ \\
Haplo & & &
\end{tabular}

Mean day of engraftment of neutrophils in group 1 was slightly faster than in group 2, however it was not statistically significant. Mean day of platelet recovery did not differ between the 2 groups (Table 2). 
Table (2): Comparison between both groups as regard engraftment of neutrophils and platelets

\begin{tabular}{|c|c|c|c|c|c|}
\hline & Group I & Group II & \multirow{2}{*}{ P-value } & \multirow{2}{*}{ Sig. } \\
\hline & & No. $=102$ & No. $=35$ & & \\
\hline \multirow{2}{*}{$\begin{array}{l}\text { Day of neutrophil } \\
\text { engraftment }\end{array}$} & Mean \pm SD & $12.91 \pm 5.67$ & $14.69 \pm 2.57$ & \multirow{2}{*}{0.090} & \multirow{2}{*}{ NS } \\
\hline & Range & $9-60$ & $11-21$ & & \\
\hline \multirow{2}{*}{ Engraftment } & No & $10(9.8 \%)$ & $3(8.6 \%)$ & \multirow{2}{*}{0.830} & \multirow{2}{*}{ NS } \\
\hline & Yes & $92(90.2 \%)$ & $32(91.4 \%)$ & & \\
\hline \multirow{2}{*}{ Platelet recovery } & Mean \pm SD & $14.67 \pm 1.89$ & $14.69 \pm 5.48$ & \multirow{2}{*}{0.984} & \multirow{2}{*}{ NS } \\
\hline & Range & $9-21$ & $10-37$ & & \\
\hline
\end{tabular}

The use of PT-CY was associated with reduced risk of extensive cGVHD (grade III - IV) in group 2 in comparison to group 1 while there was no significant difference between the 2 groups as regards incidence of aGVHD (Table $3)$.

Table (3): Comparison between both groups as regard acute GVHD and chronic GVHD

\begin{tabular}{|c|c|c|c|c|c|c|c|}
\hline & \multicolumn{2}{|c|}{ Group I } & \multicolumn{2}{|c|}{ Group II } & \multirow{2}{*}{ P-value } & \multirow{2}{*}{ Sig. } \\
\hline & & No. & $\%$ & No. & $\%$ & & \\
\hline \multirow{2}{*}{ Acute GVHD } & No & 70 & $68.6 \%$ & 25 & $71.4 \%$ & \multirow{2}{*}{0.756} & \multirow{2}{*}{ NS } \\
\hline & Yes & 32 & $31.4 \%$ & 10 & $28.6 \%$ & & \\
\hline \multirow{4}{*}{ Grade } & I & 3 & $9.4 \%$ & 1 & $10.0 \%$ & \multirow{4}{*}{0.065} & \multirow{4}{*}{ NS } \\
\hline & II & 5 & $15.6 \%$ & 5 & $50.0 \%$ & & \\
\hline & III & 11 & $34.4 \%$ & 0 & $0.0 \%$ & & \\
\hline & IV & 13 & $40.6 \%$ & 4 & $40.0 \%$ & & \\
\hline Chronic GVHD & $\begin{array}{l}\text { No } \\
\text { Yes }\end{array}$ & \multicolumn{2}{|c|}{$\begin{array}{l}44(43.1 \%) \\
58(56.9 \%)\end{array}$} & \multicolumn{2}{|c|}{$\begin{array}{c}29(82.9 \%) \\
6(17.1 \%)\end{array}$} & $<0.001$ & HS \\
\hline
\end{tabular}

Non relapse mortality was statistically higher in group 1 (Table 4$)$.

Table (4): Comparison between both groups as regard relapse, mortality and non-relapse mortality

\begin{tabular}{|c|c|c|c|c|c|c|c|}
\hline & \multicolumn{2}{|c|}{ Group I } & \multicolumn{2}{|c|}{ Group II } & \multirow{2}{*}{ P-value } & \multirow{2}{*}{ Sig. } \\
\hline & & No. & $\%$ & No. & $\%$ & & \\
\hline Relapse & $\begin{array}{l}\text { Negative } \\
\text { Positive }\end{array}$ & $\begin{array}{l}90 \\
12\end{array}$ & $\begin{array}{l}88.2 \% \\
11.8 \%\end{array}$ & $\begin{array}{c}29 \\
6\end{array}$ & $\begin{array}{l}82.9 \% \\
17.1 \%\end{array}$ & 0.416 & NS \\
\hline Mortality & $\begin{array}{l}\text { Negative } \\
\text { Positive }\end{array}$ & $\begin{array}{l}45 \\
57\end{array}$ & $\begin{array}{l}44.1 \% \\
55.9 \%\end{array}$ & $\begin{array}{l}19 \\
16\end{array}$ & $\begin{array}{l}54.3 \% \\
45.7 \%\end{array}$ & 0.298 & NS \\
\hline $\begin{array}{l}\text { Non relapse } \\
\text { mortality }\end{array}$ & $\begin{array}{l}\text { Negative } \\
\text { Positive }\end{array}$ & $\begin{array}{l}53 \\
49\end{array}$ & $\begin{array}{l}52.0 \% \\
48.0 \%\end{array}$ & $\begin{array}{l}23 \\
12\end{array}$ & $\begin{array}{l}65.7 \% \\
34.3 \%\end{array}$ & 0.158 & NS \\
\hline
\end{tabular}

Overall survival at 1 year was nearly equal in both group 1 and 2 about 57.1\%. After 3 years of follow up OS was $45.9 \%$ in group 1 and $53.6 \%$ in group 2 and with extended follow up for 5 year it decreased to $40.2 \%, 53.6 \%$ in group 1, 2 respectively (Figure 1 ). 


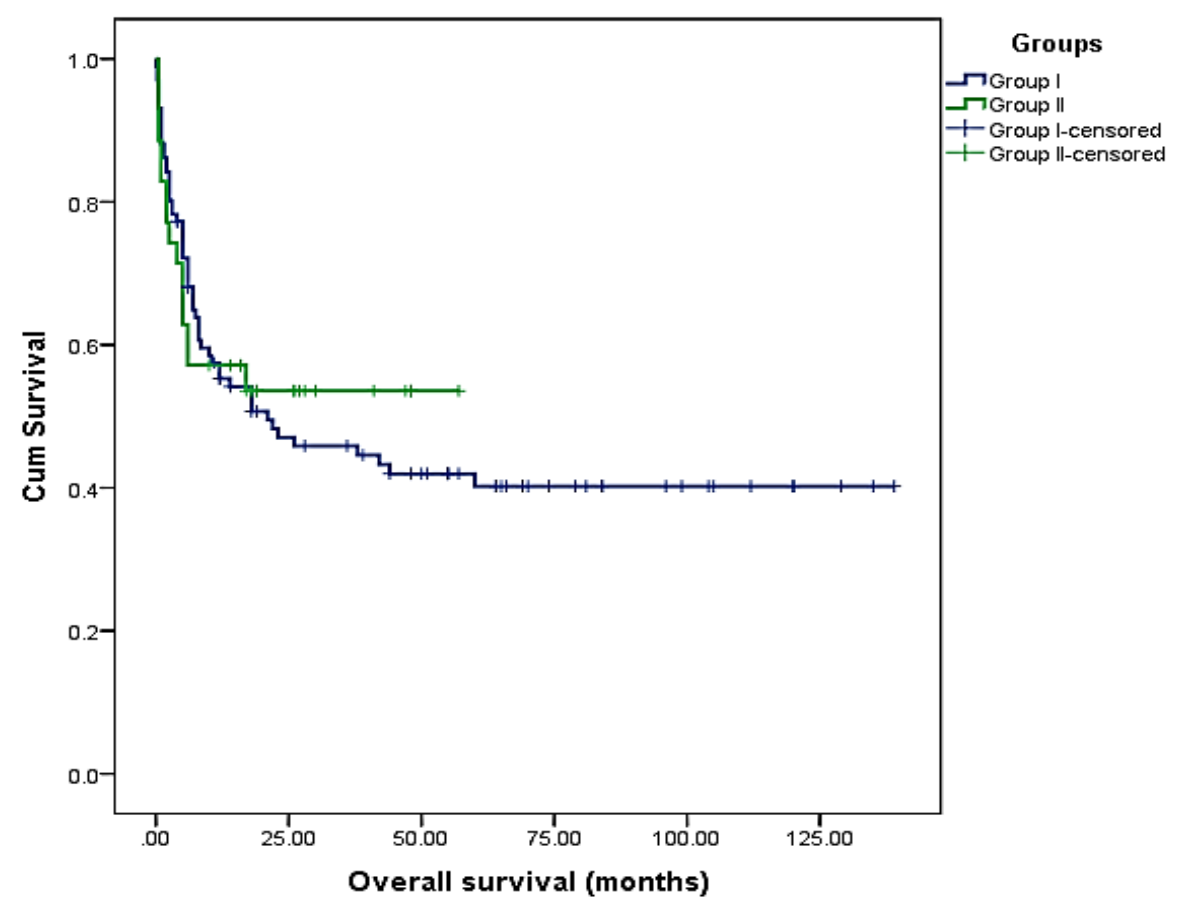

Figure (1): Comparison between both groups as regard overall survival

Disease free survival after 1 year was $87.5 \%$ in group 1 and $85.2 \%$ in group 2 . After 3 years was $81.3 \%$ in group 1 and $71.2 \%$ in group 2 and after 5 years was $81.3 \%$ in group 1 and $71.2 \%$ in group 2 (Figure 2).

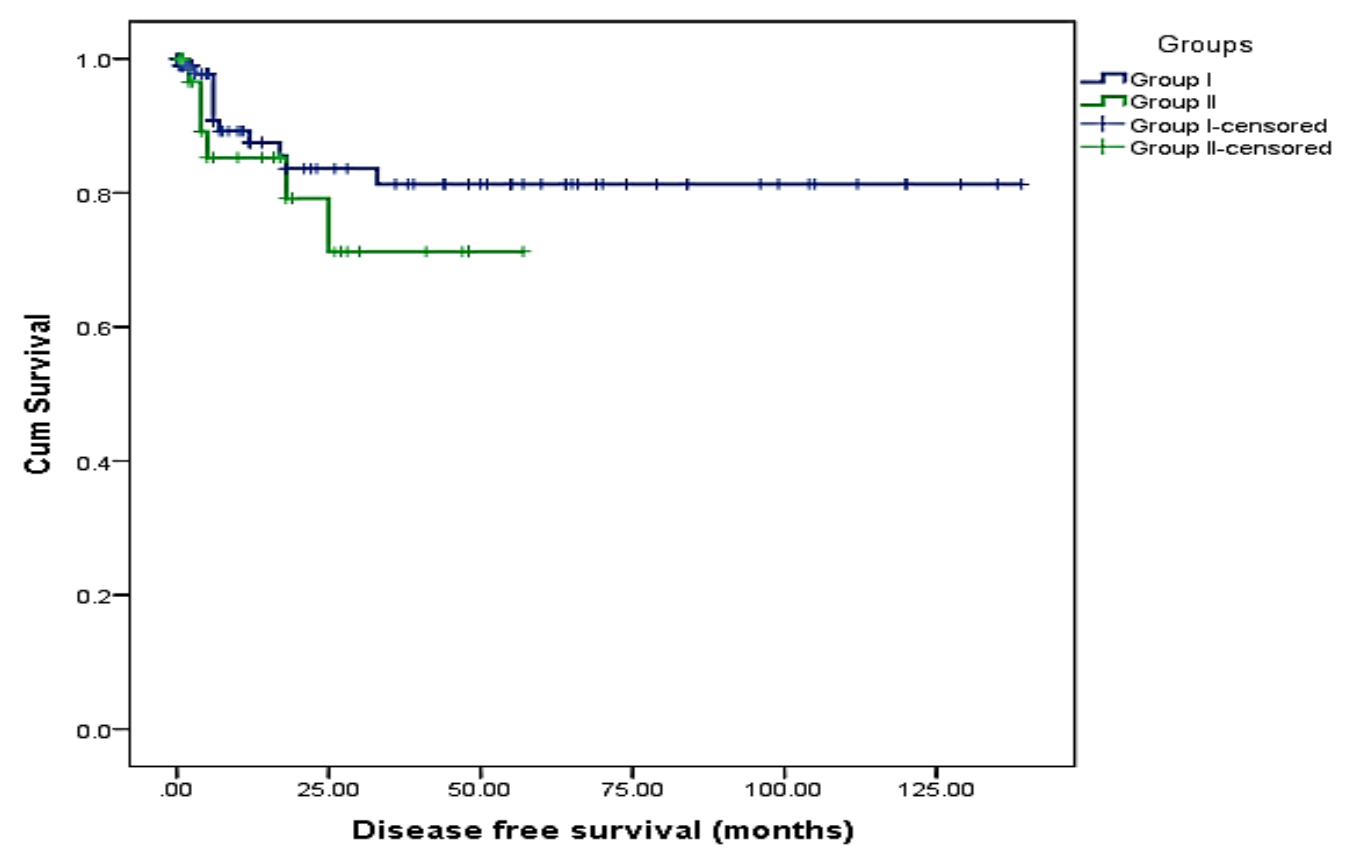

Figure (2): Comparison between both groups as regard disease free survival

\section{DISCUSSION}

Allogeneic hematopoietic stem cell transplantation (HSCT) is the main treatment procedure used to treat malignant blood diseases. Although HLA identical siblings or identical nonbound donor HLA (MUD) are ideal sources of hematopoietic stem cells, many patients may lack access to a suitable matching donor ${ }^{(8)}$. A hopeful alternative source of stem cells is the HLA- haploidentical family donor that is obtainable to nearly all patients ${ }^{(9)}$.

Though developments in immunosuppressed systems had an effect on the incidence and severity of acute GVHD, they had little effect on chronic GVHD. Chronic GVHD is the most common cause of morbidity in HSCT, occurring in approximately $70 \%$ 
of patients and managing it remains a major challenge (10).

The combination of methotrexate with calcineurin inhibitors (CNIs), such as cyclosporine remains the most commonly used regimen in GVHD prophylaxis. Although CNI-based immunosuppression has a satisfactory success in acute GVHD treatment and survival outcomes, these regimens are not totally effective, and had a significant toxicity ${ }^{(\mathbf{1 1})}$. Cyclophosphamide has been used in HSCT for its antitumor and immunosuppressive properties. Uses of high-dose cyclophosphamide posttransplant has successfully decreased GVHD in both HLA-matched and haploidentical donors ${ }^{(12)}$. Highdose post-transplantation cyclophosphamide (PT-Cy) targets alloreactive donor $\mathrm{T}$ cells that are highly proliferative early after BMT, thus minimizing the risk of severe GVHD, while still enabling survival of resting memory $\mathrm{T}$ cells that can offer protection against infection and aGVL effect ${ }^{(13)}$. Promising clinical trial data using PT-Cy with or without additional immunosuppressive agents have been used in HLA-matched related, unrelated, and haploidentical transplantation settings ${ }^{(\mathbf{1 4})}$.

We included 137 patients with mean age 31.36 \pm 7.65 and $30.22 \pm 6.74$ in group 1 and 2 respectively, who were subjected to fully matched and haploidentical allogeneic HSCT to treat hematological malignancies using myeloablative regimens according to each disease status.

There was no statistical differences between both groups as regard neutrophil engraftment and platelet recovery. Mielcarek et al. ${ }^{(\mathbf{1 5})}$ used post stem cell cyclophosphamide for prevention of GVHD with median time to platelet engraftment and neutrophil engraftment were 14 days and 19 days respectively without effect on engraftment that came in agreement with our study results. In the study performed by Rohtesh et al. (16); they compared PT-Cy with conventional methods, no statistically significant difference was detected in both groups as regard neutrophil and platelets engraftment except for mild prolongation of neutrophil and platelet engraftment in PT-Cy group than conventional methods that matched with our study results. Our results were the same as the results of Luznik et al. ${ }^{(17)}$ study who compared the outcome of patients with advanced hematological malignancies received PT-Cy in addition to MMF and tacrolimus versus methotrexate based regimen.

As regard CMV reactivation it was nearly the same results observed by Mielcarek et al. ${ }^{(15)}$

GVHD remains the main factor affecting the success of allogeneic (HSCT). Although the severity of acute GVHD have improved with good donor selection, immunosuppressive prophylaxis, however, the incidence of chronic GVHD remained about 35\% to $50 \%$. Considerable progress in the prevention of GVHD has been made as a result of the introduction of PT-Cy in allogeneic HLA-matched and haploidentical setting. The first clinical study demonstrated the role of PT-Cy as a single immunosuppressive agent in GVHD prophylaxis was held on only eleven patients which mandate further evaluation of this approach. Subsequently, the Seattle group used PT-Cy and cyclosporine as GVHD prophylaxis; and it was very effective in protection against cGVHD and decreased the NRM rates ${ }^{(\mathbf{1 0})}$.

Incidence of aGVHD in our study was $31.4 \%$, $28.6 \%$ in group 1,2 respectively, $75 \%$ of group 1 experienced grade III and IV while $40 \%$ of group 2 had grade III and IV.

PT-CY was associated with reduced risk of extensive cGVHD, which was in the same line with the study done by Kasamon et $\mathbf{a l} .{ }^{(18)}$ who compared the use of PT-Cy and MMF post HSCT with patients treated with methotrexate based regimen. Lower incidence of extensive chronic GVHD for patients receiving PT-Cy (P value 0.05$)$ also observed in the study of Al-Homsi et al. ${ }^{(19)}$, which came in agreement with our study results. Munchel $\boldsymbol{e t} \boldsymbol{a l} .{ }^{(20)}$ conducted a study on patients who were subjected to haploidentical bone marrow transplants and received PT-Cy regimen as GVHD prophylaxis. The incidence of cGVHD was lower than the incidence of aGVHD which matched with our results. Kanakry et $\boldsymbol{a l l}^{(\mathbf{( 2 1 )}}$ performed a study using cyclophosphamide as GVHD prophylaxis. He noticed lower incidence of chronic GVHD which nearly matched with our data.

The study of Bashey et al. ${ }^{(22)}$ documented that there is no difference in the incidence of GVHD in contrary to our results which reported low incidence of cGVHD in patients received PT-Cy/MM/CSA, compared with the patients received methotrexate based regimen.

In our results we experienced higher (NRM) and lower relapse rate after 2 years and higher DFS. After 3 years of follow up OS was $45.9 \%$ in group 1 and $53.6 \%$ in group 2, which is comparable to the study of Kasamon et al. ${ }^{(18)}$. In the study performed by Munchel $\boldsymbol{e t}$ al. ${ }^{(20)}$ the incidence of NRM, DFS and OS was low in comparison to our study results and higher incidence of disease relapse also was documented. In the study of Kanakry et al. ${ }^{(\mathbf{2 1})}$ they experienced lower DFS in contrary to our better results as regard the DFS. Bashey et al. ${ }^{(22)}$ found no significant difference in TRM, relapse, or survival rates between PT-CY group and methotrexate based regimen. The OS after one year of follow up in the study performed by Brunstein et al. ${ }^{(23)}$ was matched with our results in patients received PT-Cy as GVHD prophylaxis while DFS after one year of follow up in our study was better.

\section{CONCLUSION}

The use of PT-Cy for GVHD prophylaxis in HSCT reduces the risk of severe cGVHD, reducing mortality and improving overall survival. Further 
prospective randomized studies are warranted to support our results on large scale of patients received allogenic HSCT.

Conflict of interest: none (declared).

Acknowledgement: This research did not receive any specific grants from funding agencies in the public, and not for profit sectors.

\section{REFERENCES}

1. Welniak L, Blazar B, Murohy W (2007): Immunobiology of allogeneic hematopoietic stem cell transplantation. Annu Rev Immunol., 25: 139-170.

2. Storb R, Deeg H, Whitehead J et al. (1986): Methotrexate and cyclosporine for prophylaxis of acute graft versus host disease after marrow transplantation for leukemia. N Engl J Med., 314:729-735.

3. Cutler C, Li S, Ho V et al. (2007): Extended follow-up of methotrexate-free immunosuppression using sirolimus and tacrolimus in related and unrelated donor peripheral blood stem cell transplantation. Blood, 109:3108-14.

4. Strauss G, Osen W, Debatin K (2002): Induction of apoptosis and modulation of activation and effector function in $\mathrm{T}$ cells by immunosuppressive drugs. Clin Exp Immunol., 128:255-266.

5. Glucksberg H, Storb R, Fefer A et al. (1974): Clinical manifestations of graft-versus-host disease in human recipients of marrow from HL-A-matched sibling donors. Transplantation, 18:295-304.

6. Shulman H, Sullivan K, Weiden P et al. (1980): Chronic graft-versus-host syndrome in man. A long-term clinicopathologic study of 20 Seattle patients. American Journal of Medicine, 69:204-217.

7. Przepiorka D, Weisdorf D, Martin P et al. (1995): 1994 consensus conference on acute GVHD Grading. Bone Marrow Transplantation, 15:825-828.

8. Appelbaum F, Forman S, Robert R et al. (2011): Thomas' Hematopoietic Cell Transplantation., chapter 96, Lung injury following Hematpoietic cell Transplantation, Kenneth R Cooke \& Gregory A Yanik Fourth Edition., Blackwell Publishing Ltd. https://www.perlego.com/book/1014199/thomashematopoietic-cell-transplantationpdf?queryID=4101671f2e1a78b82b6f11a0874546ae\&sear chIndexType=topics\&searchPosition $=9$

9. Reisner Y, Hagin D, Martelli M (2011): Haploidentical hematopoietic transplantation: current status and future perspectives. Blood, 118 (23): 6006-17.

10. Flowers M, Inamoto $Y$, Carpenter $P$ et al. (2009): Comparative analysis of risk factors for acute graft-versushost disease and for chronic graft-versus-host disease according to National Institutes of Health consensus criteria. Blood, 117:3214-19.

11.Edinger M, Hoffmann P, Ermann $J$ et al. (2003): $\mathrm{CD} 4+\mathrm{CD} 25+$ regulatory $\mathrm{T}$ cells preserve graft-versus-tumor activity while inhibiting graft-versus-host disease after bone marrow transplantation. Nat Med., 9(9):1144-50.
12. Kanakry C, Tsai H, Bolaños-Meade J et al. (2014): Single-agent GVHD prophylaxis with post transplantation cyclophosphamide after myeloablative, HLA-matched BMT for AML, ALL, and MDS. Blood, 124(25):3817-27.

13. Ganguly S, Ross D, Panoskaltsis Mortari A et al. (2014): Donar CD4+ Foxp3+regulatory $\mathrm{T}$ cell are necessary for post-transplant cyclophosphamide mediated protection against GVHD in mice. Blood, 124: 2131-41.

14. McCurdy S, Kanakry J, Showel M et al. (2015): Riskstratified outcomes of non-myeloablative HLAhaploidentical BMT with high-dose post-transplantation cyclophosphamide. Blood, 125(19):3024-31.

15. Mielcarek M, Furlong T, O'Donnell P et al. (2016): Post-transplantation cyclophosphamide for prevention of graft-versus-host disease after HLA-matched mobilized blood cell transplantation. Blood, 127(11):1502-08.

16. Rohtesh S, Rima M, Julianne C et al. (2016): Posttransplantation cyclophosphamide versus conventional graft-versus-host disease prophylaxis in mismatched unrelated donor haematopoietic cell transplantation. $\mathrm{Br} \mathbf{J}$ Hematol., 173: 444-455.

17. Luznik L, O'Donnell P, Symons H et al. (2008): HLAhaploidentical bone marrow transplantation for hematologic malignancies using nonmyeloablative conditioning and high-dose, post-transplantation cyclophosphamide. Biol Blood Marrow Transplant. 14:641-650

18. Kasamon Y, Luznik L, Leffell M et al. (2010): Nonmyeloablative HLA-haploidentical bone marrow transplantation with high-dose Post-transplantation cyclophosphamide: effect of HLA disparity on outcome. Biol Blood Marrow Transplant, 16:482-489.

19. Al-Homsi A, Tara S, Kelli C et al. (2015): PostTransplant High-Dose Cyclophosphamide for the Prevention of Graft-versus-Host Disease. Biol Blood Marrow Transplant, 21: 604-611.

20. Munchel A, Kesserwan C, Symons H et al. (2011): Nonmyeloablative HLA haploidentical bone marrow transplantation with high dose post-transplantation cyclophosphamide. Pediatr Rep., 3(2):43-47

21. Kanakry C, O'Donnell P, Furlong T et al. (2013): Posttransplantation cyclophosphamide following busulfan and fludarabine myeloablative conditioning prevents severe acute and chronic graft-versus-host disease and minimizes duration of immunosuppression: results of a multi-institutional trial in patients with high-risk hematologic malignancies. Blood, 122:3310-15.

22. Bashey A, Zhang X, Sizemore C et al. (2013): T-cell replete HLA-haploidentical hematopoietic transplantation for hematologic malignancies using posttransplantation cyclophosphamide results in outcomes equivalent to those of contemporaneous HLA-matched related and unrelated donor transplantation. J Clin Oncol., 31:1310-16.

23. Brunstein C, Fuchs E, Carter S et al. (2011): Alternative donor transplantation after reduced intensity conditioning: results of parallel phase 2 trials using partially HLA-mismatched related bone marrow or unrelated double umbilical cord blood grafts. Blood, 118:282-288. 